\title{
Erratum to: Accuracy of Cardiac Auscultation in Asymptomatic Neonates with Heart Murmurs: Comparison Between Pediatric Trainees and Neonatologists
}

\author{
Ageliki A. Karatza - Sotirios Fouzas • \\ Sotirios Tzifas • Alexandra Mermiga • \\ Gabriel Dimitriou · Stefanos Mantagos
}

Published online: 13 March 2011

(C) Springer Science+Business Media, LLC 2011

Erratum to: Pediatr Cardiol

DOI 10.1007/s00246-011-9905-z

The original version of this article unfortunately contained a mistake. The author names were incorrect. The corrected author names are presented here.

The online version of the original article can be found under doi:10.1007/s00246-011-9905-z.

\footnotetext{
A. A. Karatza $\cdot$ S. Fouzas $(\bowtie) \cdot S$. Tzifas $\cdot$ A. Mermiga

G. Dimitriou $\cdot$ S. Mantagos

Neonatal Intensive Care Unit, Department of Pediatrics,

University Hospital of Patras, Patras, Greece

e-mail: sfouzas@gmail.com
} 